Borgsteede SD, Deliens L, Graafland-Riedstra C, Francke AL, van der Wal G, Willems DL.

\begin{tabular}{|c|c|}
\hline stprint Version & 1.0 \\
\hline Journal website & 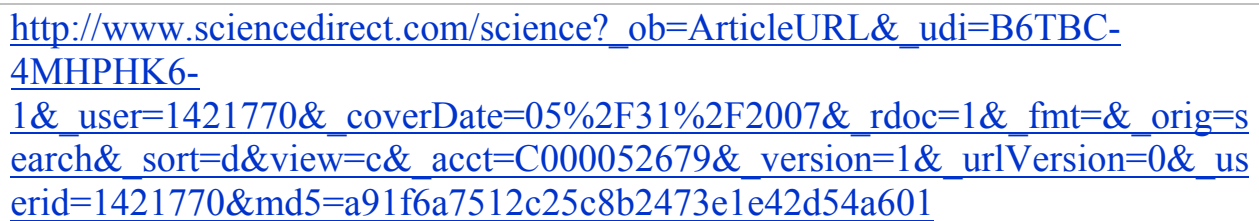 \\
\hline Pubmed link & $\begin{array}{l}\text { http://www.ncbi.nlm.nih.gov/sites/entrez?Db=pubmed\&Cmd=ShowDetailView } \\
\text { \&TermToSearch=17158015\&ordinalpos=1\&itool=EntrezSystem2.PEntrez.Pubm } \\
\text { ed.Pubmed_ResultsPanel.Pubmed_RVDocSum }\end{array}$ \\
\hline DOI & 06.10 .006 \\
\hline
\end{tabular}

This is a NIVEL certified Post Print, more info at http://www.nivel.eu

\title{
Communication about euthanasia in general practice: Opinions and experiences of patients and their general practitioners
}

\author{
SANDER D. BorgsteEdeA, LuC Deliensa, B, CORRIE GraAfland-RiEdSTRAa, ANNEKE L. \\ FRANCKEC, GERRIT VAN DER WALA AND DICK L. WILLEMSD
}

a VU University Medical Center, Department of Public and Occupational Health, EMGO Institute, Amsterdam, The Netherlands

b Vrije Universiteit Brussel, End-of-Life Care Research Group, Brussels, Belgium

c Netherlands Institute for Health Services Research, Utrecht, The Netherlands

d University of Amsterdam, Department of General Practice, Academic Medical Center, Amsterdam, The Netherlands

\begin{abstract}
Objective : Public opinion and professional organisations dominate the euthanasia debate, and there is a need to understand the opinions of people confronted with euthanasia. The aim of this study was to investigate whether patients and their GPs talk about euthanasia, and if so, how they communicate about this.

Methods: Qualitative, semi-structured interviews were held with 20 GPs and 30 of their patients in primary care in the Netherlands, where euthanasia is legalised. The patients had a life expectancy of less than 6 months, and cancer, heart failure or chronic obstructive pulmonary disease as underlying disease.

Results: Many patients did not communicate about euthanasia with their GP. Neither the patient nor the GP were clear in formulating their expectations concerning future decision making.

Conclusion: The initial patient-GP communication consisted of an exchange of opinions about situations in which euthanasia would be desirable. GPs had different opinions about who should initiate communication, and found it difficult to judge the right moment to talk.

Practice implications: It is essential to pay attention to education in communication about dying and euthanasia and to train the GPs to gain insight in the patient's end-of-life preferences, and to direct care at the best possible quality of life.
\end{abstract}


Borgsteede SD, Deliens L, Graafland-Riedstra C, Francke AL, van der Wal G, Willems DL.

Communication about euthanasia in general practice: opinions and experiences of patients and their general practitioners.

Patient Education and Counseling. Vol. 66, 2006, nr. 2, p. 156-161.

\section{INTRODUCTION}

Health care in the Netherlands is characterized by a strong emphasis on primary care, where the GP is the central professional in the management and co-ordination of the patient's treatment [1]. Almost $60 \%$ of patients with a non-acute illness die at home [2], and there is general consensus that palliative care should be provided there [3]. In 2001, death was preceded by end-of-life decision making in approximately $40 \%$ of all cases [4]. While $7 \%$ of patients had made an explicit request for euthanasia or assisted suicide, $2.6 \%$ of all deaths were the result of euthanasia. GPs performed euthanasia more frequently than all other doctors [4].

In the Netherlands, euthanasia is legal and is defined as an act, undertaken by a third party, which intentionally ends the life of a person at his or her request [5]. This decision is taken within the doctorpatient relationship, and societal control has been incorporated into post-death review procedures [6]. Prudent practice is required of doctors and this includes the patient being well informed about diagnosis, prognosis, and treatment options [6]. Moreover, both doctor and patient must be convinced that there is no other reasonable option. In this process, communication between patient and doctor is essential.

The status of euthanasia in relation to palliative care is not clear: some authors claim that euthanasia can be part of palliative care [7], but most argue that there is no place for euthanasia in palliative care [8]. The same standpoint is adopted in the World Health Organisation (WHO) definition, which states that palliative care 'intends neither to hasten nor postpone death' [9]. The European Association of Palliative Care (EAPC) ethics task force says that 'individual requests for euthanasia require respect, careful attention, together with open and sensitive communication', and 'provision of euthanasia should not be part of the responsibility of palliative care' [10]. This makes the status of communication about euthanasia in palliative care ambiguous: while the two are considered incompatible, communication becomes essential. More insight is essential for a better understanding of the complex relationship between euthanasia and palliative care.

In the current debate on euthanasia where the voices of professional organisations and politicians have been dominant, there is need for more understanding of the subjective experiences of those involved [11]. Due to legalisation in the Netherlands, euthanasia can be one potential result of the communication process. In this context, we investigated the opinions of doctors and patients regarding good end-of-life care, using a qualitative design in primary care [12]. This paper investigates an important research question that came up during that study: do terminally ill patients and their GPs talk about euthanasia and, if so, how do they communicate about it, for instance about what topics and on whose initiative.

\section{METHODS}

\subsection{GP selection}

Of 49 GPs following an intensive postgraduate course in end-of-life care, organised by the Dutch College of General Practitioners, [13] and [14] 17 agreed to participate in this study. To represent the opinions of GPs who were not trained in end-of-life care, and the opinions of their patients, we extended our sample: the GPs who agreed to participate were asked to invite a colleague in the same district with no specific interest in end-of-life care to participate also. A total of 14 GPs with no specific interest in end-of-life care agreed, resulting in 31 GPs taking part, 20 of whom included one or more patient.

\subsection{Patient selection}

After enrolment in the study, the GPs were asked to select for inclusion the first patient they encountered who met the following criteria: (1) a life-expectancy of less than 6 months; (2) cancer, heart failure or chronic obstructive pulmonary disease (COPD) as underlying disease; (3) the GP as (one of) the primary caregiver(s); (4) an adequate command of the Dutch language. GPs who, for any reason, did not select a patient who met the inclusion criteria, were asked to give their reasons for not doing so. If a patient met the inclusion criteria, the GP briefly described the study to them, and handed over an envelope containing an information sheet. The investigators (SDB and CGR) then made an appointment with the patient for an interview. Before the interview the patient was asked to give informed consent. If the patient could not or did not want to participate, the GP was asked to select the 
Borgsteede SD, Deliens L, Graafland-Riedstra C, Francke AL, van der Wal G, Willems DL.

Communication about euthanasia in general practice: opinions and experiences of patients and their general practitioners.

Patient Education and Counseling. Vol. 66, 2006, nr. 2, p. 156-161.

next patient who met the inclusion criteria. We aimed to include the opinions of both cancer patients and patients with the other two terminal diseases most frequently presented in general practice: heart failure and COPD [2].

\subsection{Interviews}

Semi-structured, in-depth interviews were carried out in the patient's home. During most of these interviews a partner or relative was present. The interviews with the first 12 patients and those with their GPs, started with the goal of exploring the aspects of end-of-life care at home most valued by both patients and GPs [12]. As is usual in qualitative research, interim analysis steered subsequent data-collection and analysis. During the interim analysis we found that communication about euthanasia was an interesting topic in most interviews. In subsequent interviews, we aimed to investigate this further, and therefore added the following questions: (1) did you talk (with your GP/with your patient) about euthanasia, and in the GP interviews (2) how do you communicate with patients in general about euthanasia? If the answer to the first question was positive, we asked the interviewee to elaborate.

Approximately 2 weeks after the patient interview, the GP was interviewed according to a similar topic list. No information from the patient interview was revealed to the GP. All interviews were audio-taped, transcribed verbatim, and rendered anonymous. The investigators read the transcript while listening to the interview to ensure textual accuracy. The transcripts of the interviews then served as data.

The interviewers were an academic researcher/pharmacist (SDB) and a health scientist (CGR). Prior to the interviews, both had followed an interview course, and during the interview period they were supervised by experienced qualitative researchers (ALF and DLW).

\subsection{Analysis}

All interview transcripts were analysed with the support of QSR Nvivo 2.0, an established software package for ordering qualitative data. The fragments concerning euthanasia from all interviews were identified and coded by the two researchers according to themes that patients and GPs considered to be important. During the analysis, the validity was ensured by critical discussion and by searching for cases, which seemed either to verify or contradict the insights derived from the interim analysis.

\section{RESULTS}

\subsection{Patient characteristics}

Between January 2002 and August 2003, 20 GPs recruited 31 patients receiving end-of-life care; one patient could not be interviewed because her condition suddenly worsened. A total of $11 \mathrm{GPs}$, six of whom were on the end-of-life care course, did not recruit any patient. In the interviews the GPs reported that 13 patients had not been selected, even though they met the inclusion criteria. They gave the following reasons for not selecting a patient: very short life expectancy; cognitively, physically or emotionally unable to be interviewed; communication problems between patient and GP; and denial of terminal illness.

During the study, patients with heart failure and COPD proved to be more difficult to recruit. As we had a limited time-frame in which to hold the interviews, we asked all GPs, including those who had already included a patient, to select other patients with heart failure or COPD who met the inclusion criteria in order to achieve our aim of including not only cancer patients. As a result, 14 GPs each included one patient, 3 GPs included two, 2 GPs included three and 1 GP included four patients.

Table 1 summarizes the characteristics of the patients and the GPs who were interviewed. Half the patients were between 70 and 80 years old, and more men than women were interviewed. Of the 14 non-cancer patients, seven had heart failure, four had COPD and three had both illnesses. In 25 patient-interviews euthanasia was a topic, and in 14 of these the patient and GP communicated about euthanasia (Table 2).

\section{TABLE 1.}




\section{TABLE 2.}

\subsection{Aspects emerging from the analysis}

Four main aspects of communication about euthanasia emerged from the interviews: (1) many patients did not communicate about euthanasia, (2) future decision making, (3) clarifying and finetuning, and (4) initiative and timing.

Most quotations concerning euthanasia were from GPs. These reflect their experiences with euthanasia during their career, but do not necessarily involve communication with the patient(s) they had included in this study. The reason for this was that the patient and the GP had often not had extensive communication about it. The GPs found that problems around euthanasia usually arose closer to the end-of-life. There was no indication that whether the GP was or was not trained in endof-life care made any difference.

\subsubsection{Many patients did not communicate about euthanasia}

Table 2 shows that 11 out of 25 patients did not communicate about euthanasia. For many patients euthanasia was not an issue in their end-of-life trajectory, and therefore they did not feel it was necessary to talk about it. Sometimes patients had religious reasons for not wanting to talk about euthanasia:

I don't want to talk about euthanasia. Man proposes, God disposes. There's nothing to decide about (Patient, male, 78, COPD and heart failure).

GPs said they often did not initiate communication with patients who were religious. However, there were religious patients who wanted to talk about euthanasia, and requested euthanasia.

Table 2 also shows that communication about euthanasia was more frequent with cancer patients than with non-cancer patients. This matched the experiences of GPs, that euthanasia was more frequently a topic of communication with cancer patients:

With them (patients with COPD or heart failure) you tend less to talk about euthanasia. Studies show how difficult it is to predict when someone with heart failure or COPD will die. And to say to them a year before they die: 'What would you prefer when things get worse?' that's something you don't do. So it might sound strange, but it doesn't happen. (GP, cared for patient, male, 82 years heart failure.)

\subsubsection{Future decision making}

In one interview, communication concerned an actual request for euthanasia. All other communications concerned future decision making. Patients and GPs exchanged opinions about situations, which could give rise to euthanasia requests. In some cases the communication was a (written) statement from the patient that he no longer wanted to live if the suffering was unbearable. Handing over a written request was not experienced as proper communication by one GP; a detailed discussion was a prerequisite to the communication process.

When talking about euthanasia, patients had in mind situations in which their life would no longer be worth living. They often had an idea about how they did or did not want to die. The fear they expressed involved physical aspects of suffering such as pain:

I wrote a request for euthanasia in the presence of Dr. E., she signed it, and I also signed it. She's willing. I just wrote down that if I become paralysed, or if the pain is unbearable, and if I become a poor, little, ill woman, confined to bed, then she is prepared to give me euthanasia. (Patient, 55, female, breast cancer.)

However, not all requests from patients were as clear as this. GPs were confronted by rather vague, more general requests:

Patients often make indirect statements such as: 'Doctor, you won't let me down, will you?' Well, what do they mean by such a statement, and how should we react? What do they expect? (GP, cared for patient, 55, female, breast cancer.)

GPs mentioned that patients did not only speak about euthanasia; discussion was accompanied by exploring other end-of-life situations, which provided insight into the patient's end-of-life preferences. 
Borgsteede SD, Deliens L, Graafland-Riedstra C, Francke AL, van der Wal G, Willems DL.

Communication about euthanasia in general practice: opinions and experiences of patients and their general practitioners.

Patient Education and Counseling. Vol. 66, 2006, nr. 2, p. 156-161.

\subsubsection{Clarifying and fine-tuning}

In a typical response to a request, GPs promised they would support patients in the performance of euthanasia, on the condition that when the situation arose, the GP and the patient must both agree that it was the best option:

Quite soon (after the diagnosis) the possibility of euthanasia was discussed in detail with him and his wife. He clearly stated that he didn't want to go through hell and that when life really becomes unbearable, he will ask me for (active) euthanasia. I agreed, on the condition that I must also be convinced. (GP, cared for patient, 60, male, lung cancer.)

Neither the patients nor the GPs were very clear in formulating their expectations about the conditions under which euthanasia would be performed. The following quote illustrates that communication often involved a general exchange of expectations:

We talked about it (euthanasia) and my GP agrees. 'Not for some time', she says, 'at the moment, you can still handle it.' But as soon as it becomes too bad, I will say: 'please bring this to an end'. (Patient, 86, male, stomach cancer.)

An important aspect of communication was the clarification of the euthanasia question. What do the words 'unbearable' or 'inhumane' mean? Do patient and GP have the same view of what would justify euthanasia? One GP foresaw a potential dilemma. The patient and GP had not yet explored their views on what they meant by 'unbearable', hence it was unclear what they expected from each other:

I told him that if the suffering really becomes unbearable, I think that he should not have to live any longer, but that I would do anything to make his life bearable. There are many possibilities, but I haven't met a patient whose life became unbearable. At that moment we were both satisfied, and he had no further questions. It might become a problem when we reach a situation in which I think life is still worth living, and he doesn't. (GP, cared for patient, 75, male, mesothelioma.)

Monitoring changes in opinion during the illness trajectory was important. A patient who said that she wanted euthanasia at the onset of her disease, changed her mind during the illness trajectory. Her GP expected that in the end, she would not require euthanasia.

\subsubsection{Initiative and timing}

Most GPs left the initiative to talk about euthanasia to their patients, but were sensitive to signals that might indicate a patient's wish to talk:

I have developed the policy that as long as people don't raise the subject (euthanasia) themselves, I won't be the one to start talking, although I am sensitive to signals. As soon as there is any indication, I will raise the subject. (GP, cared for patient, 75, male, oesophagus cancer.)

Other GPs initiated the subject when they foresaw problems in the near future:

Whether I raise the topic of euthanasia, depends on the situation. For example, with someone who has larynx carcinoma that can close up the throat, I raise the topic sooner and more actively in case that occurs. Then everybody knows: what is preferred in that case. (GP, cared for patient, 80, male, COPD.)

GPs stated that it was difficult to judge the right moment for communication about euthanasia. Some GPs took initiatives themselves to plan future activities, to co-ordinate care, and to communicate about the patient's preferences.

Another aspect according to some GPs was that they wanted to be sensitive and talk about the subject without suggesting that they promoted euthanasia:

When the end of life is near, I want to make euthanasia a topic of consideration. However, I don't want to put the words into their mouth. I'm always afraid that people will feel: 'I must have euthanasia or else I'll be a burden for the doctor or for everybody else.' A request for euthanasia must come from the people themselves, when they feel there's no way out. (GP, cared for patient, 68, male, lung cancer.)

Both patients and GPs acknowledged that it was an advantage if the GP had known the patient for a longer period and shared a common history, and if they could communicate in the patient's home. 
Borgsteede SD, Deliens L, Graafland-Riedstra C, Francke AL, van der Wal G, Willems DL.

Communication about euthanasia in general practice: opinions and experiences of patients and their general practitioners.

Patient Education and Counseling. Vol. 66, 2006, nr. 2, p. 156-161.

\section{DISCUSSION AND CONCLUSION}

\subsection{Discussion}

We interviewed patients and GPs in one of the few countries in which euthanasia is legalised.

Patients prepare themselves for a (worst case) scenario in which they might consider euthanasia. At the same time, GPs also anticipate the worst case scenario: a situation in which they are requested to administer lethal drugs. GPs had different opinions about whether they should initiate communication, and found it difficult to judge the right moment to do so.

The strengths of this study is that we interviewed both patients and their GPs, using a similar topic list. We included GPs with and without special interest in end-of-life care, and patients with cancer and non-cancer as underlying disease. We assured the patients that the information would remain confidential and that confidentiality was guaranteed to their own GP.

Obviously, our study has some limitations. The GPs admitted that they had selected patients who they thought were suitable to be interviewed. Hence, we probably interviewed patients who were relatively healthy and satisfied with their GP. Due to good patient-doctor contact, euthanasia might be easier to talk about, and the GP more sensitive in reacting to signals. GPs mentioned their experiences with communication about euthanasia during their careers, while one interview was held with each patient. Hence, we collected more data on the experiences of GPs than of patients. Yet, given these limitations, we are of the opinion that they do not change the meaning of our findings.

In other countries, apart from Belgium, the performance of euthanasia is illegal and communication about euthanasia is less frequent [15]. In studies directed at end-of-life communication the main barriers doctors identified were associated with the timing of communication, [16] an aspect also found in our study. Most of the GPs we interviewed were careful, and some were reluctant, to initiate communication about euthanasia, and approximately half of the patients communicated with them on this subject. In the context of euthanasia as one of the end-of-life options, we might have expected more communication.

We also expected that more GPs would have initiated communication, because patients should be informed about all possible options to enable them to make informed decisions [17]. It seems that the fact that euthanasia is legal does not make it any easier to initiate communication about it. In our opinion, open communication may result in agreement between patient and doctor on whether to perform euthanasia or not. With this in mind, it is unclear what the EAPC and WHO mean by open communication about euthanasia in the context of the explicit exclusion of the act [9] and [10].

\subsection{Conclusion}

The initial communication between patient and GP consists of an exchange of opinions about possible situations in which euthanasia is desirable. GPs have different opinions about whether communication should be initiated by the patient or the GP, and find it difficult to judge the right moment to talk about euthanasia.

\subsection{Practice implications}

Since talking about death is experienced as difficult by doctors [18], it is essential to pay more attention to train in communication about death, dying and euthanasia [19]. Communication should be directed at end-of-life decisions that are allowed in each specific regional setting. Not only to make good decisions, but also to gain insight in the patient's end-of-life preferences that will allow doctors to direct care towards the best possible quality of life and death.

\section{REFERENCES}

[1] Health Council of the Netherlands, European primary care. 2004/20E, Health Council of the Netherlands, The Hague (2004).

[2] A.L. Francke and D.L. Willems, Palliatieve zorg vandaag en morgen [Palliative care today and tomorrow], Elsevier gezondheidszorg, Maarssen (2000).

[3] R.J. Janssens and H.A. Ten Have, The concept of palliative care in the Netherlands, Palliat Med 15 (2001), pp. 481-486. 
Borgsteede SD, Deliens L, Graafland-Riedstra C, Francke AL, van der Wal G, Willems DL.

Communication about euthanasia in general practice: opinions and experiences of patients and their general practitioners.

Patient Education and Counseling. Vol. 66, 2006, nr. 2, p. 156-161.

[4] B.D. Onwuteaka-Philipsen, A. Van der Heide, D. Koper, I. Keij-Deerenberg, J.A. Rietjens and M.L. Rurup et al., Euthanasia and other end-of-life decisions in the Netherlands in 1990, 1995, and 2001, Lancet 362 (2003), pp. 395-399.

[5] L. Deliens and G. Van der Wal, The euthanasia law in Belgium and the Netherlands, Lancet 362 (2003), pp. 1239-1240.

[6] G. Van der Wal, J.Th.M. Van Eijk, H.J. Leenen and C. Spreeuwenberg, Euthanasia and assisted suicide II. Do Dutch family doctors act prudently?, Fam Pract 9 (1992), pp. 135-140.

[7] C. Van der Meer, Euthanasia: a definition and ethical conditions, J Palliat Care 4 (1988), pp. 103106.

[8] M.A. Hermsen and H.A. Ten Have, Euthanasia in palliative care journals, J Pain Symptom Manage 23 (2002), pp. 517-525.

[9] WHO, National cancer control programmes: policies and managerial guidelines, World Health Organization, Geneva (2002).

[10] L.J. Materstvedt, D. Clark, J. Ellershaw, R. Forde, A.M. Gravgaard and H.C. Muller-Busch et al., Euthanasia and physician-assisted suicide: a view from an EAPC ethics task force, Palliat Med 17 (2003), pp. 97-101.

[11] Y.Y. Mak, G. Elwyn and I.G. Finlay, Patients' voices are needed in debates on euthanasia, Brit Med J 327 (2003), pp. 213-215.

[12] S.D. Borgsteede, C. Graafland-Riedstra, L. Deliens, A.L. Francke, Van Eijk JThM and D.L. Willems, Good end-of-life care according to patients and their GPs, Brit J Gen Pract 56 (2006), pp. 20-26.

[13] Kaderopleiding Palliatieve Zorg. De eerste ervaringen kaderopleiding palliatieve zorg [Executive training palliative care. primary experiences]. Huisarts en Wet 2004;44:522.

[14] Kaderopleiding voor huisartsen [Executive training for general practitioners]. Pallium 2001;June/July:8-9.

[15] E.J. Emanuel, D.L. Fairclough and L.L. Emanuel, Attitudes and desires related to euthanasia and physician-assisted suicide among terminally ill patients and their caregivers, J Am Med Assoc 284 (2000), pp. 2460-2468.

[16] J.R. Curtis, D.L. Patrick, E.S. Caldwell and A.C. Collier, Why don't patients and physicians talk about end-of-life care? Barriers to communication for patients with acquired immunodeficiency syndrome and their primary care clinicians, Arch Intern Med 160 (2000), pp. 1690-1696.

[17] M. Hermsen and H. Ten Have, Decision making in palliative care practice and the need for moral deliberation: a qualitative study, Patient Educ Couns 56 (2005), pp. 268-275.

[18] E.J. Emanuel, D.L. Fairclough, P. Wolfe and L.L. Emanuel, Talking with terminally ill patients and their caregivers about death, dying, and bereavement: is it stressful? Is it helpful?, Arch Intern Med 164 (2004), pp. 1999-2004.

[19] R. Deschepper, R. VanderStichele, J.L. Bernheim, E. De Keyser, G. Van der Kelen and F. Mortier et al., Communication on end-of-life decisions with patients wishing to die at home: the making of a guideline for GPs in Flanders, Belgium, Brit J Gen Pract 56 (2006), pp. 14-19. 
Borgsteede SD, Deliens L, Graafland-Riedstra C, Francke AL, van der Wal G, Willems DL.

Communication about euthanasia in general practice: opinions and experiences of patients and their general practitioners.

Patient Education and Counseling. Vol. 66, 2006, nr. 2, p. 156-161.

\section{TABLES}

Table 1.

Demographic, clinical and practice characteristics of interviewees (30 patients and $20 \mathrm{GPs}$ )

\begin{tabular}{|c|c|c|}
\hline & Patients $(n=30)$ & GPs $(n=20)$ \\
\hline Male gender & $19(63 \%)$ & $11(55 \%)$ \\
\hline Median age (range) & $78(49-93)$ & - \\
\hline \multicolumn{3}{|l|}{ Underlying disease } \\
\hline Cancer & $16(53 \%)$ & - \\
\hline Non-cancer & $14(47 \%)$ & - \\
\hline Median years of experience as a GP (range) & - & $20.5(6-33)$ \\
\hline Palliative care training & - & $11(55 \%)$ \\
\hline Solo practice & - & $8(40 \%)$ \\
\hline
\end{tabular}

Table 2.

Patient and GP characteristics of all patients who mentioned euthanasia in the interview $(n=25)$

\begin{tabular}{|c|c|c|c|}
\hline & \multicolumn{2}{|c|}{$\begin{array}{l}\text { Did patient and GP communicate } \\
\text { about euthanasia? }\end{array}$} & \multirow[t]{2}{*}{$\begin{array}{l}\text { All patients who mentioned euthanasia in the } \\
\text { interview }(n=25)\end{array}$} \\
\hline & Yes $(n=14)$ & No $(n=11)$ & \\
\hline \multicolumn{4}{|c|}{ Patient characteristics } \\
\hline \multicolumn{4}{|c|}{ Underlying disease } \\
\hline Cancer & 10 & 2 & 12 \\
\hline Non-cancer & 4 & 9 & 13 \\
\hline \multicolumn{4}{|l|}{ Gender } \\
\hline Male & 10 & 6 & 16 \\
\hline Female & 4 & 5 & 9 \\
\hline \multicolumn{4}{|l|}{ Age } \\
\hline$\leq 78$ years & 7 & 3 & $10^{\underline{\mathbf{a}}}$ \\
\hline$>78$ years & 7 & 8 & 15 \\
\hline
\end{tabular}


Borgsteede SD, Deliens L, Graafland-Riedstra C, Francke AL, van der Wal G, Willems DL.

Communication about euthanasia in general practice: opinions and experiences of patients and their general practitioners.

Patient Education and Counseling. Vol. 66, 2006, nr. 2, p. 156-161.

\begin{tabular}{|c|c|c|c|}
\hline & \multicolumn{2}{|c|}{$\begin{array}{l}\text { Did patient and GP communicate } \\
\text { about euthanasia? }\end{array}$} & \multirow{2}{*}{$\begin{array}{l}\text { All patients who mentioned euthanasia in the } \\
\text { interview }(n=25)\end{array}$} \\
\hline & Yes $(n=14)$ & No $(n=11)$ & \\
\hline \multicolumn{4}{|c|}{ GP characteristics of these patients } \\
\hline \multicolumn{4}{|c|}{ Training in palliative care } \\
\hline Yes & 9 & 9 & $18^{\underline{b}}$ \\
\hline No & 5 & 2 & 7 \\
\hline \multicolumn{4}{|c|}{ Years of experience } \\
\hline$\leq 20$ & 6 & 5 & 11 \\
\hline$>20$ & 8 & 6 & 14 \\
\hline
\end{tabular}

${ }^{a}$ Most younger patients had cancer $(n=6$ out of 10$)$ and most older patients did not have cancer as underlying disease ( $n=9$ out of 15$)$.

${ }^{\mathrm{b}}$ GPs trained in palliative included more non-cancer patients ( $n=11$ out of 18$)$ and GPs no trained in palliative included more cancer patients $(n=5$ out of 7$)$. 